Jurnal Manajemen Teori dan Terapan | Tahun 2, No.1, April 2009 | Sri Gunawan, Rosa Rilantiana dan Sony Kusumasondjaja

\title{
PENGARUH PERSEPSI DESAIN TOKO TERHADAP STORE REPATRONAGE INTENTIONS DENGAN SHOPPING EXPERIENCE COSTS SEBAGAI INTERVENING DI TOKO ELEKTRONIK "X" SURABAYA
}

\author{
Sri Gunawan*, Rosa Rilantiana** dan Sony Kusumasondjaja* \\ *Departemen Manajemen, Fakultas Ekonomi, Universitas Airlangga \\ ** Alumni Fakultas Ekonomi, Universitas Airlangga
}

\begin{abstract}
ABSTRAK
Pelanggan memiliki keinginan untuk menyentuh produk yang akan dibeli agar dapat merasakan tekstur, berat dan besarnya produk tersebut sehingga memberikan pengalaman pada tangan (hands-on experience). Ritel yang menerapkan konsep hands-on display memperbolehkan pengunjung untuk menyentuh dan merasakan semua produk yang dipajang. Hal ini dianggap sarana yang baik dalam memberikan informasi kepada pelanggan tentang teknologi terbaru. Penelitian ini berfokus pada desain speciality store yang menerapkan konsep hands-on display yaitu Toko Elektronik " $X$ " Surabaya dan pengaruhnya terhadap store repatronage intentions dengan variabel intervening shopping experience costs. Berdasarkan analisis data terhadap 212 responden yang berbelanja pada toko elektronik " $X$ " diperoleh hasil pengaruh yang signifikan antara persepsi desain toko berpengaruh terhadap store repatronage intentions dan shopping experience costs. Sedangkan shopping experience costs tidak berpengaruh terhadap store repatronage intentions.
\end{abstract}

Kata kunci : Desain toko, shopping experience costs, store repatronage intention, hands-on display

\section{PENDAHULUAN}

Desain sebuah toko memiliki peran penting karena lingkungan (seluruh fisik sekitar maupun benda-benda yang memiliki bentuk) dapat memberikan pengaruh pada perilaku pelanggan (Bitner, 1990, 1992; Wikström, 2005). Pelanggan mencari tempat yang menurut mereka menarik (Jones dan Reynolds, 2006) dan juga dapat menyediakan pengalaman berbelanja yang menyenangkan bagi mereka (Baker dkk, 2002). Menurut Berman dan Evans (2001:454) lingkungan toko dapat mempengaruhi kenikmatan berbelanja, sama seperti waktu yang dihabiskan untuk mencari, berbicara dengan staf penjual, kecenderungan untuk berbelanja lebih 
banyak dari pada rencana dan kemungkinan untuk berlangganan (patronage). Beberapa orang membentuk kesan (impression) sebelum memasuki atau baru saja memasuki area fasilitas, memberikan penilaian sebelum meneliti barang dan harganya.

Hasil dari penelitian Gross yang dikutip oleh Greenland dan McGoldrick (2000) mengidentifikasi bahwa $80 \%$ dari informasi eksternal berasal dari mata yang didapat dari perhatian atas aspek visual. Aspek visual tersebut adalah penataan lingkungan yang dilihat dapat memberikan penjelasan dan pengertian (Botschen dan Crowther, 1999; Greenland dan McGoldrick, 2000). Akan tetapi saat ini pelanggan memiliki keinginan untuk menyentuh sama halnya dengan mereka melihat, sehingga dapat merasakan tekstur, berat dan besarnya suatu benda yang memberikan pengalaman pada tangan (hands-on experience). Salah satu penemuan Underhill yang dikutip oleh Kotler (2004) tentang perancangan ruang toko yakni mengatur agar produk bisa disentuh. Sebuah toko dapat menawarkan bermacam-macam produk berkualitas dari yang paling murah ataupun paling menarik tetapi jika pelanggan tidak dapat menyentuh atau mencobanya, sebagian daya tarik produk akan hilang.

Pelanggan saat ini tidak hanya berbelanja untuk memenuhi kebutuhannya saja, tetapi pelanggan yang berorientasi pada rekreasi akan mencari toko yang memberikan pengalaman menyenangkan. Dengan demikian pelanggan memiliki memiliki harapan yang dipengaruhi oleh pengalaman pembelian mereka sebelumnya. Baker dkk (2002) menyatakan bahwa pada saat evaluasi terhadap lingkungan toko yang terdiri dari desain, sosial dan lingkungan ambient dilakukan oleh pelanggan, mereka kenyakinan bahwa lingkungan ini memberikan informasi tentang atribut product-related seperti kualitas, harga, dan pengalaman berbelanja (the shopping experience), yang kerap disebut sebagai shopping experience costs (Baker, dkk., 2002). Persepsi 
dari shopping experience costs ini adalah pengalaman berbelanja yang membentuk persepsi pelanggan dari waktu (time) dan usaha (effort) yang mereka korbankan dengan berbelanja pada sebuah toko serta psychic cost yang membentuk stres dan emosional saat berbelanja.

Penelitian ini bertujuan untuk mengetahui pengaruh Persepsi Konsumen atas Desain Toko yang menggunakan konsep hand-on display terhadap Shopping Experience Cost dan Repatronage Intention pada toko electronik "X". Penelitian ini mengadopsi penelitian yang dilakukan oleh Baker dkk. (2002) dengan menggunakan setting pada toko yang menggunakan konsep hands-on display.

\section{LINGKUNGAN TOKO (Store Environment)}

Lingkungan toko memiliki pengaruh besar pada pelanggan, karena lingkungan toko menawarkan pemandangan yang memberikan informasi kepada pelanggan yang nantinya memberikan penilaian atas produk dan jasa. Jika iklan dibuat dengan tujuan menginformasikan, menarik, memikat atau mendorong pelanggan untuk datang ke toko, maka store environment berperan penting untuk memikat pembeli, membuat nyaman pelanggan dalam berbelanja dan mengingatkan produk-produk yang perlu dimiliki baik untuk pribadi maupun keperluan rumah tangga (Ma'ruf, 2005: 201).

Menurut Baker (2002) terdapat tiga komponen dasar dari store environment:

(1) Ambien, mengacu pada pada kondisi latar belakang seperti kualitas udara, suara, wangi-wangian dan kebersihan; (2) Desain, meliputi komponen aesthetic(arsitektur, warna, skala, material, tekstur, bentuk, gaya dan aksesoris) dan fungsional dan dapat diterapkan pada interior ataupun eksterior dari organisasi jasa; serta (3) Sosial, yaitu orang-orang yang berada pada lingkungan yang terdiri dari para pelanggan dan para staf toko. 


\section{Desain Toko}

Mendesain toko dengan baik sama halnya dengan menulis sebuah cerita yang menarik untuk dibaca. Menurut Baker (1986) bahwa desain adalah elemen fungsional dan astetis, seperti arsitektur, style dan layout. Dengan desain yang baik akan menarik orang untuk mengetahui lebih jauh apa yang terdapat di dalan toko tersebut.

Menurut Meyo (2000), Lingkungan toko sangat mempengaruhi keputusan pembelian konsumen, karena 70 - 80\% pengambilan keputusan pembelian dilakukan di dalam toko pada saat pelanggan mengamati barang yang ada di toko.

Sebuah toko yang memberikan kenyamanan serta atraktif akan menarik pelanggan melalui dekorasi toko, layout dan musik pengiring yang tidak hanya memberi gambaran tentang toko, tetapi akan mendorong pelanggan untuk tinggal lebih lama di dalam toko (Meyo, 2000). Desain toko yang baik akan menarik keinginan pelanggan untuk mengetahui segala sesuatu yang terdapat pada toko tersebut. Suasana toko dapat dibangun melalui pengaturan tata letak dan penataan produk yang dijual. Toko yang memberikan kesenangan dan lingkungan yang atraktif melalui pendekatan-pendekatan perasaan akan menciptakan sebuah lingkungan kompetitif antar toko dalam memberikan pengalaman pelanggan di dalam toko dan dipastikan dapat menarik banyak pelanggan pada toko ( Moye, 2000; Frasquet et al., 2002; Andreu dkk, 2006).

\section{Konsep Hands-On Display}

Lewison (1994) menyatakan bahwa store environment berhubungan dengan kelima

panca indra (penglihatan, pendengaran, penciuman, peraba serta perasa). Peritel dapat menggunakan pendekatan melalui panca indra ini untuk mempengaruhi gambaran dan 
kesenangan dalam berbelanja (Lewison, 1994). Sebagai contoh, peritel menggunakan penglihatan untuk membangun perhatian pelanggan. Penggunaan dari pendekatan penglihatan dapat terpenuhi dengan menciptakan keselarasan, pembandingan, atau pembedaan visual pada display, layout, atau pengaturan fisik toko. Semakin kreatif penataan, maka semakin menarik display tersebut dan semakin diingat oleh pelanggan (Hughes, 2005).

Lingkungan ritel perlu menyediakan dan memfasilitasi indra peraba dari pelanggan. Layout, peralatan, perlengkapan dan display toko perlu untuk memperbolehkan pelanggannya memeriksa secara personal (Lewison, 1994). Melalui konsep Hands-on display, pengunjung diperbolehkan untuk menyentuh dan merasakan semua produk yang dipajang, juga merupakan sarana yang baik dalam memberikan informasi kepada pelanggan tentang teknologi terbaru (Marketing, 2004: 3; Hughes, 2005). Produk-produk yang ada bisa dilihat, disentuh, dan dirasakan oleh pelanggan agar lebih yakin dan percaya pada produk elektronik seperti home theater dan audio yang akan dibelinya.

Banyaknya pilihan membuat pemilihan toko menjadi kompleks. Toko yang menjadi pilihan dari pelanggan bergantung dari seberapa baik harapan pelanggan mengenai toko tersebut dibandingkan persepsi yang didapat dari toko alternatif tersedia. Desain sebuah toko memiliki peran penting karena lingkungan (seluruh fisik sekitar maupun benda-benda yang memiliki bentuk) dapat memberikan pengaruh pada perilaku pelanggan (Bitner, 1990, 1992; Wikström, 2005). Bagi pelanggan yang mencari produk spesifik, fokus mereka adalah kemudahan untuk menemukan toko yang tepat tanpa harus menjelajahi seluruh toko yang ada (Kok Wing dan Linda, 2005). 
Desain toko dapat mempengaruhi store repatronage intentions (Fishbein dan Ajzen, 1975; Jones dan Reynolds, 2006). Menurut Jones dan Reynolds (2006) bahwa pelanggan memberikan nilai tinggi pada store repatronage intentions pada sebuah toko yang menarik. Seseorang yang tertarik pada sebuah objek, akan mencaritahu dan berusaha untuk berinteraksi dengan objek tersebut (Izard, 1977; Ortony dan Tunner 1990; Jones dan Reynolds, 2006).

Berdasarkan uraian tersebut, maka disusun Hipotesis sebagai berikut:

Hipotesis 1: Persepsi konsumen atas Desain Toko yang menggunakan konsep hands-on display berpengaruh terhadap store repatronage intentions di Toko Elektronik "X".

\section{SHOPPING EXPERIENCE COSTS}

Pengalaman adalah kumpulan titik dimana toko dan pelanggan saling menukar rangsangan (stimuli), informasi dan emosi yang dapat ditanamkan pada suatu produk, digunakan untuk meningkatkan pelayan atau menciptakan kesatuan itu sendiri (Schimitt, 1999: 60).

Menurut Broekhuizen dan Jager, dalam Baker (2002) shopping experience merupakan bagian terpenting dari keputusan membeli dan toko hendaknya membangun melalui kenikmatan (enjoyment) yang dirasa. Konsep shopping experience ini berkaitan dengan biaya yang dikeluarkan oleh konsumen pada saat mengalami pengalaman berbelanja (Baker, 2002).

Baker dkk (2002) mengindentifikasi dua jenis shopping experience costs yaitu timeleffort cost perceptions dan psychic cost perceptions. Persepsi dari shopping experience costs ini adalah pengalaman berbelanja yang membentuk persepsi pelanggan dari waktu (time) dan usaha (effort) 
yang mereka habiskan dengan berbelanja pada sebuah toko serta psychic cost yang membentuk stres dan emosional saat berbelanja.

\section{Time/Effort Cost Perceptions}

Timeleffort cost perceptions adalah persepsi pelanggan atas waktu serta usaha untuk berbelanja yang dibutuhkan saat mencari barang yang dibutuhkan. Hal ini diperkuat oleh Baker (2002) bahwa “time/effort cost perceptions construct captures consumers' perceptions of time and effort they are likely to expend shopping at a store".

Waktu (time) sangatlah berharga bagi setiap orang. Bagi beberapa orang, waktu yang digunakan untuk mendapatkan barang lebih penting dari pada uang yang dikeluarkan untuk mendapatkan barang (Engel, Blackwell and Miniard, 1995; Khan, 2007). Pelanggan jenis ini tidak suka membuang sia-sia waktunya, oleh sebab itu, pelanggan mempersepsikan time dan efford sebagai nonmonetary cost.

Usaha (effort) timbul sebagai dampak pencarian dan pemenuhan kebutuhan dari pelanggan. Pelanggan akan membutuhkan lebih usaha di lingkungan yang tidak pernah atau jarang dikunjungi untuk mencari dan mendapatkan barang yang dibutuhkan, dibandingkan pada lingkungan yang sudah sering dikunjungi. Pada lingkungan yang sudah sering dikunjungi, pelanggan telah memiliki informasi sehingga membutuhkan lebih sedikit usaha untuk mencari maupun mendapatkan barang yang dibutuhkannya.

Zeithaml (2000) menyatakan bahwa pelanggan mengharapkan tujuan berbelanjanya dengan minimum time dan effort. Para peneliti lainnya (Schary, 1971; Marmorstein, Grewal and Fishe 1992; Baker dkk, 2002) menyatakan bahwa waktu dan usaha untuk mencari dan mendapatkan barang maupun jasa memiliki nilai ekonomis bagi pelanggan. 


\section{Psychic Cost Perceptions}

Baker dkk (2002) mendefinisikan dibentuknya psychic cost sebagai tekanan mental pelanggan dan emosional pegawai saat terbentuknya pengalaman berbelanja (shopping experience). Fokus makna cost dari psychic cost adalah reaksi negatif pelanggan pada lingkungan toko dimana pelanggan memenuhi kebutuhannya.

Lingkungan toko dapat memberikan pengaruh positif maupun pengaruh negatif. Pengaruh positif dari lingkungan toko antara lain meningkatnya perasaan senang, sedangkan pengaruh negatif lingkungan toko yang buruk (contoh: penataan layout toko yang membingungkan) dapat mengakibatkan berkurangnya kenikmatan berbelanja dan mengakibatkan

Desain dapat mempengaruhi harapan pelanggan atas kemudahan bergerak di toko yang bertujuan untuk kemudahan untuk masuk serta keluar, mencari barang dengan mudah, juga memberikan rasa senang dalam berbelanja. Baker dkk (2002) menyatakan bahwa pada saat evaluasi terhadap lingkungan toko yang terdiri dari desain, sosial dan lingkungan ambient dilakukan oleh pelanggan, mereka berkenyakinan bahwa lingkungan ini memberikan informasi tentang atribut product-related seperti kualitas, harga, dan pengalaman berbelanja (the shopping experience).

Pelanggan akan memutuskan apa yang hendak dilakukan pada masa mendatang ketika menerima pengalaman. Pengalaman diperoleh pelanggan pada saat berada di dalam toko dan dari pengalaman tersebut tersebut, maka pelanggan melaksanakan evaluasi atas apa yang akan dilakukan. Evaluasi yang dilaksanakan oleh pelanggan adalah evaluasi atas harapan yang diinginkan dibandingkan dengan keadaan sesungguhnya. 
Perasaan pelanggan saat memperoleh pengalaman berbelanja dapat merangsang intentions positif untuk jangka pendek (contoh: keinginan berada lebih lama di dalam toko) dan intentions positif jangka panjang (misalnya, repatronage intentions) (Donovan and Rossiter, 1982; Hui et al., 1997; Lemmink and Mattson, 1998; Andreu, 2006; Jones and Reynolds, 2006).

Keputusan untuk menjadi pelanggan (patronize) pada beberapa toko menurut Meyo (2000) biasanya berawal dari karakteristik atau atribut yang dirasa penting oleh pelanggan dan terjadi saat dipenuhi keinginan dan kebutuhannya pada sebuah toko. Pengalaman berbelanja yang berbeda dan tidak didapat dari tempat berbelanja lain, maka menimbulkan keinginan pada pelanggan tetap berbelanja pada toko yang sama.

Persepsi dari shopping experience costs ini adalah pengalaman berbelanja yang membentuk persepsi pelanggan dari waktu (time) dan usaha (effort) yang mereka habiskan dengan berbelanja pada sebuah toko serta psychic cost yang membentuk stres dan emosional saat berbelanja. Kemudian persepsi shopping experience costs tersebut akan berpengaruh pada store repatronage intention ((Donovan and Rossiter, 1982; Hui dkk, 1997; Lemmink and Mattson, 1998; Andreu, 2006; Jones and Reynolds, 2006). Pelanggan memiliki keinginan atas cost yang timbul ketika mereka berbelanja, sehingga ketika memasuki sebuah toko mereka telah memilih harapan untuk dipenuhi dan dievaluasi. Evaluasi pelanggan atas pengalamannya mempengaruhi terbentuknya keputusan untuk berniat melanjutkan menjadi pelanggan toko (store patronize) dan komitment untuk repatronage dimasa mendatang (Arnould dkk, 2002).

Berdasarkan uraian tersebut maka dapat disusun hipotesis sebagai berikut: 
Hipotesis 2: Persepsi Konsumen atas Desain Toko berpengaruh terhadap Shopping Experience Costs, yang terdirid dari Timeleffort Cost Perceptions dan Psychic Cost $\backslash$ Perceptions di Toko Elektronik "X".

Hipotesis 3: Shopping Experience Costs, yang terdiri dari Timeleffort Cost Perceptions dan Psychic Cost Perceptions berpengaruh terhadap Store Repatronage Intentions di Toko Elektronik " $\mathrm{X}$ "

\section{METODA PENELITIAN}

\section{Pemilihan Sampel}

Jumlah sampel yang diambil dalam penelitian ini adalah 212 pelanggan yang pernah berbelanja di Toko Elektronik "X".

Teknik yang digunakan dalam mengambil sampel adalah non-probability sampling. Penarikan sampel dilakakukan secara purposive sampling yaitu memilih sampel secara sengaja kepada subyek yang tidak hanya sebagai pelaku langsung, akan tetapi memahami permasalahan penelitian yang menjadi fokus peneliti).

\section{PengukuranVariabel}

Store repatronage intentions yang dimaksud pada penelitian ini adalah keinginan pelanggan untuk mengulang perilaku yaitu berbelanja kembali pada suatu retailer pada masa yang akan datang ( Jones dan Reynolds, 2006). Variabel Store Repatronage Inmtentions diukur dengan menggunakan alat ukur yang digunakan oleh Maxham dan Netemeyer (2002) serta Jones dan Reynolds (2006).

Desain Toko didefinisikan sebagai persepsi pelanggan atasadalah elemen fungsional dan estetis, seperti arsitektur, style dan layou dari Toko Elektronik "X". Variabel ini diukur dengan menggunakan alat ukur yang dikembangkan oleh Baker dkk ( 2002)

Persepsi dari shopping experience costs adalah pengalaman berbelanja yang membentuk persepsi pelanggan dari waktu (time) dan usaha (effort) yang mereka habiskan dengan berbelanja pada sebuah toko serta psychic cost yang membentuk stres dan emosional saat berbelanja 
(Baker, dkk., 2002). Indikator yang digunakan untuk mengukur variabel ini diadaptasi dari indikator yang dikembangkan oleh Baker, dkk (2002).

\section{Teknik Analisis}

Pengujian Hipotesis penelitian dilakukan dengan menggunakan teknik analisis Structural Equation Modeling dengan menggunakan software AMOS 5.0

\section{HASIL PENELITIAN}

Responden penelitian ini terdiri dari 95 orang pria, dan 117 orang wanita, yang sebagian besar merupakan karyawan swasta (45,3\%); dengan distribusi umur sebagai berikut:

\section{Tabel 1.}

Distribusi Umur Responden

\begin{tabular}{|c|c|c|c|}
\hline No & Usia & Jumlah & Prosentase \\
\hline 1 & $15-24$ tahun & 57 & 26.9 \\
\hline 2 & $25-34$ tahun & 72 & 34.0 \\
\hline 3 & $35-44$ tahun & 50 & 23.6 \\
\hline 4 & $45-54$ tahun & 25 & 11.8 \\
\hline 5 & $\geq 55$ tahun & 8 & 3.8 \\
\hline \multicolumn{2}{|c|}{ Jumlah } & $\mathbf{2 1 2}$ & $\mathbf{1 0 0 . 0}$ \\
\hline
\end{tabular}

\section{Hasil Uji Validitas}

Uji Validitas dilakukan dengan jalan melakukan analisis Faktor. Hasil pengujian dengan analisis Faktor terhadap tiga Konstruk yang digunakan dalam penelitian ini, menunjukkan bahwa semua konstruk tersebut dinyatakan valid karena mempunyai factor loadings $\geq 0,5$.

\section{Hasil Uji Reliabilitas}

Dalam penelitian ini reliabilitas kuisioner diukur melalui teknik pengukuran reliabilitas konsistensi internal dengan menghitung cronbach alpha $(\alpha)$. Hasil pengujian dengan cronbach alpha $(\alpha)$ menunjukkan bahwa semua variabel penelitian dinyatakan reliabel. 
TABEL 2

Reliabilitas

\begin{tabular}{|l|c|c|l|}
\hline \multicolumn{1}{|c|}{ Variabel } & Alpha & Nilai Kritis & Keterangan \\
\hline Desain Toko (X) & 0.765 & 0.6 & Reliabel \\
\hline Shopping Experience Costs (Y) & 0.848 & 0.6 & Reliabel \\
\hline Store Repatronage Intentions (Z) & 0.877 & 0.6 & Reliabel \\
\hline
\end{tabular}

\section{Hasil Uji Model Struktural}

Hasil pengujian model structural dengan AMOS 5.0 dapat dilihat pada gambar 1 berikut ini

\section{Gambar 1}

Struktural Model Pengaruh Desain Toko terhadap Repatronage Intentions

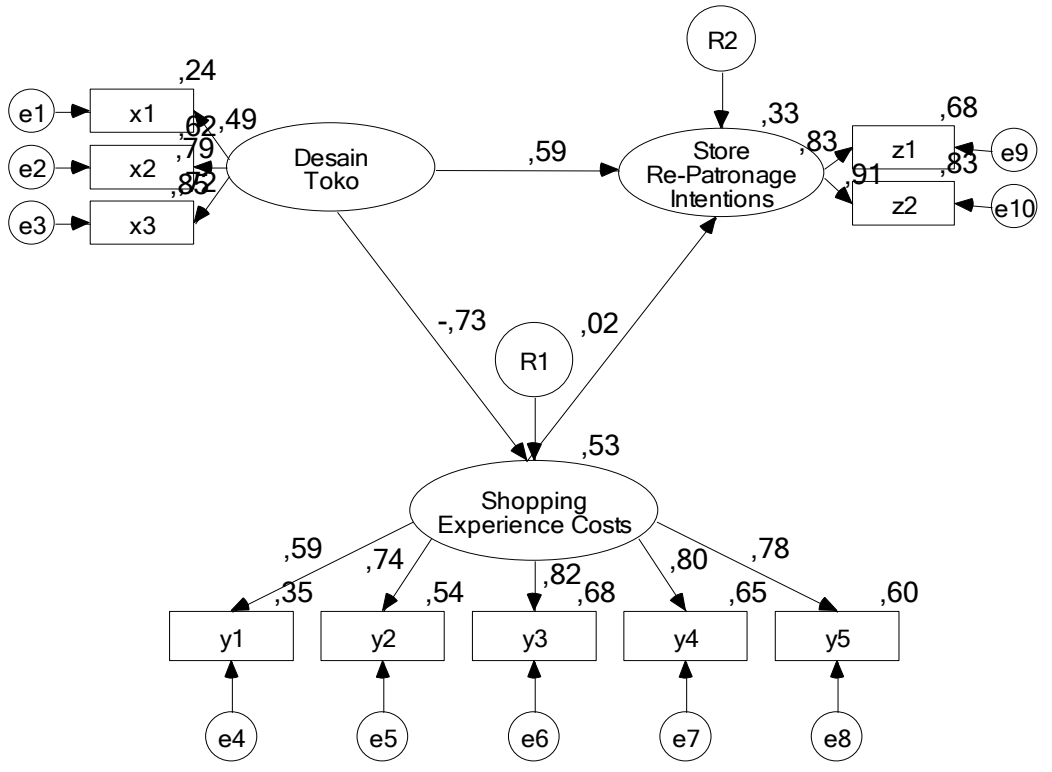

Model Struktural pada gambar 1 tersebut dinyatakan dapat diterima sesuai dengan beberapa kriteria Goodness of Fit index, walaupun beberapa index mempunyai nilai marginal $(\mathrm{CMIN} / \mathrm{DF} \mathrm{m}=3,341, \mathrm{GFI}=0,900, \mathrm{IFI}=0,927, \mathrm{CFI}=0,926, \mathrm{NFI}=0,898)$. 


\section{Pengujian Hipotesis}

Parameter hubungan kasualitas antara konstruk yang dihipotesiskan dianalisis denganmenggunakan kriteria critical ratio yang identik dengan uji t. Pengaruh antar konstruk yang dihipotesiskan dapat dilihat pada table 3 berikut ini

Tabel 3

Hubungan Struktural, Critical Ratio dan Standardized Regression Weight

\begin{tabular}{|c|c|c|c|c|c|c|}
\hline & & & Estimate & C.R & Prob. & $\begin{array}{c}\text { Standardize Reg. } \\
\text { Weight }(\lambda)\end{array}$ \\
\hline $\mathrm{Z}$ & $<--$ & $\mathrm{X}$ & $-0,574$ & $-8,523$ & 0,000 & $-0,731$ \\
\hline $\mathrm{y}$ & $<-$ & $\mathrm{Z}$ & 0,016 & 0,139 & 0,890 & 0,017 \\
\hline $\mathrm{y}$ & $<-$ & $\mathrm{X}$ & 0,414 & 4,461 & 0,000 & 0,588 \\
\hline
\end{tabular}

Tabel 3 menunjukkan bahwa nilai C.R desain toko terhadap store repatronage intentions adalah 4,461, dengan nilai koefisien path desain toko terhadap store repatronage intentions adalah positif yaitu sebesar 0.588, sehingga dapat disimpulkan bahwa Desain Toko berpengaruh positif dan signifikan terhadap Store Repatronage Intentions.

Tabel 3 menunjukkan bahwa nilai C.R desain toko terhadap shopping experience costs adalah $-8,523$ sedangkan nilai koefisien path desain toko terhadap shopping experience costs adalah negatif yaitu sebesar 0,731, sehingga dapat disimpulkan bahwa desain toko berpengaruh negatif dan signifikan terhadap shopping experience costs.

Tabel 3menunjukkan bahwa nilai C.R shopping experience costs terhadap store repatronage intentions adalah 0,139 , dengan probabilitas $=0,890$, sehingga dapat disimpulkan bahwa shopping experience costs tidak berpengaruh terhadap store repatronage intentions.

\section{PEMBAHASAN}


Secara teori bahwa penciptaan suasana (atmospherics) berarti desain lingkungan melalui komunikasi visual, pencahayaan, warna, musik dan wangi-wangian untuk menciptakan respon emosional, persepsi pelanggan dan mempengaruhi pelanggan dalam meningkatkan kemungkinan membeli barang (Utami,2006: 238; Kotler, 1973). Desain sebuah toko memiliki peran penting karena lingkungan (seluruh fisik sekitar maupun benda-benda yang memiliki bentuk) dapat memberikan pengaruh pada perilaku pelanggan (Bitner, 1990, 1992; Wikström, 2005).

Desain toko merupakan bukti fisik tempat pelanggan dan peritel mengadakan transaksi. Persepsi desain toko dapat mempengaruhi store repatronage intentions (Fishbein dan Ajzen, 1975; Jones dan Reynolds, 2006). Menurut Jones dan Reynolds (2006) bahwa pelanggan memberikan nilai tinggi pada store repatronage intentions pada sebuah toko yang menarik. Seseorang yang tertarik pada sebuah objek, akan mencaritahu dan berusaha untuk berinteraksi dengan objek tersebut (Yard, 1977; Ortony dan Tunner, 1990; Jones dan Reynolds, 2006).

Selain berpengaruh terhadap keinginan untuk melakukan pembelian ulang, Desain toko juga berpengaruh terhadap shopping experience cost. Berdasarkan hasil pengolahan data yang dilakukan disimpulakn bahwa terdapat pengaruh negatif yang signifikan antara persepsi desain toko terhadap persepsi shopping experience costs. Keserasian warna interior, penataan barang dagangan dan kemudahan untuk bergerak di Toko Elektronik " $\mathrm{X}$ " mampu mempengaruhi waktu untuk mendapatkan barang yang dibutuhkan, usaha mencari letak barang yang dibutuhkan, ketidaksukaan suasana toko, ketidaksesuaian harapan pada suasana toko dan kenyamanan pada saat belanja. di Toko Elektronik "X".

Menururt Lovelock (2005: 216) bahwa bukti fisik dapat menciptakan efek, dengan menggunakan warna dan tektur, suara, bau dan desain ruang untuk menciptakan selera untuk 
barang jasa atau pengalaman. Persepsi desain toko akan mempengaruhi shopping experience costs

Zeithaml (2000) menyatakan bahwa pelanggan mengharapkan tujuan berbelanjanya dengan minimum time dan effort. Para peneliti lainnya (Schary, 1971; Marmorstein, Grewal and Fishe 1992; Baker dkk, 2002) menyatakan bahwa waktu dan usaha untuk mencari dan mendapatkan barang maupun jasa memiliki nilai ekonomis bagi pelanggan.

Elektronik terus mengalami kemajuan, sehingga pelanggan cenderung bingung dan membutuhkan waktu untu mempelajari feature yang ditawarkan (Burke, 2000). Desain toko rumit dapat membingungkan pelanggan, sehingga membutuhkan waktu serta usaha lebih dan juga menimbulkan tekanan emosional untuk memperoleh barang yang dibutuhkan (Baker, 2002). Toko Elektronik "X" dengan konsep hands-on display, berusaha menciptakan desain tokonya memberikan pengalaman yang menarik dan atraktif dengan memperbolehkan pelanggannya untuk melihat, menyentuh dan merasakan, sehingga pelanggan menikmati serta menggunakan efisien waktu dan usaha yang dibutuhkan untuk memperoleh barang kebutuhannya.

Penelitian ini menolak Hipotesis yang menyatakan bahwa Shopping experience cost berpengaruh terhadap Store Repatronage Intentions. Waktu untuk mendapatkan barang yang dibutuhkan, usaha mencari letak barang yang dibutuhkan, ketidaksukaan suasana toko, ketidaksesuaian harapan pada suasana toko dan kenyamanan pada saat belanja di Toko Elektronik " $\mathrm{X}$ " tidak mampu mempengaruhi niat pelanggan untuk berbelanja dan kemungkinan pelanggan untuk berkunjung kembali di Toko Elektronik "X" pada masa datang.

Secara teori pelanggan akan memutuskan apa yang hendak dilakukan pada masa mendatang ketika menerima pengalaman. Pengalaman diperoleh pelanggan pada saat berada di 
dalam toko dan dari pengalaman tersebut, maka pelanggan melaksanakan evaluasi atas apa yang akan dilakukan.

Perasaan pelanggan saat memperoleh pengalaman berbelanja dapat merangsang intentions positif untuk jangka pendek (contoh : keinginan berada lebih lama di dalam toko) dan intentions positif jangka panjang (contoh: repatronage intentions) (Donovan dan Rossiter, 1982; Hui dkk, 1997; Lemmink and Mattson, 1998; Andreu, 2006; Jones and Reynolds, 2006).

Banyaknya produk yang ditawarkan dan banyaknya pelanggan yang berkunjung khususnya pada akhir minggu, mengakibatkan pelanggan kurang menikmati pencarian barang kebutuhannya; seperti kemudahan bergerak; dan pengalaman berbelanja dengan konsep handson display yang ditawarkan menjadi kurang maksimal. Pelanggan menginginkan kenyamanan berbelanja, seperti kemudahan untuk masuk dan keluar toko dan menemukan barang yang dibutuhkan dengan cepat (Baker, 2002). Penuhnya toko membuat pelanggan berpersepsi bahwa mereka akan memerlukan waktu lebih lama untuk mendapatkan barang yang dibutuhkan, sehingga pelanggan tidak melalui proses informasi-informasi yang di tawarkan saat memasuki toko (Baker, 2002). Pelanggan juga dapat dipengaruhi oleh hal lain pada saat memasuki ataupun saat berada di area toko. Hal lain tersebut seperti para tenaga penjual (sales persons) yang berada di area toko, variasi produk yang ditawarkan, juga daya tarik promosi dalam toko.

Baker (2002) menyatakan bahwa tenaga penjualan memiliki peranan penting dalam mempengaruhi mood dan keinginan, juga respon pelanggan. Tenaga penjual dapat mempengaruhi persepsi waktu/usaha (timeleffort) dan psikologis yang pelangan korbankan, sebagai contoh tenaga penjual yang membantu mencarikan barang kebutuhan dengan ramah ataupun memberikan pelayanan yang cepat akan memberikan pengaruh positif bagi pelanggan 
(Wakefield dan Blodgett, 1999; Baker, 2002), sedangkan buruknya pelayanan tenaga penjualan toko, seperti kurang ramah dalam menyampaikan informasi produk sehingga pelangan menjadi kehilangan keinginan untuk berbelanja. Variasi produk yang ditawarkan dan daya tarik promosi dalam toko dapat menarik pelanggan untuk berkunjung, karena pelanggan dapat membandingkan produk-produk yang paling tepat untuk memenuhi kebutuhan. Menurut Jones dan Reynolds (2006) bahwa pelanggan akan semakin tertarik pada sebuah toko, jika kategori produk yang tersedia sangat dibutuhkan oleh pelanggan tersebut.

\section{SIMPULAN DAN SARAN}

Penelitian ini bertujuan untuk menguji pengaruh Desain Toko yang menggunakan konsep Hands-on display terhadap Shopping Experience Cost dan Repatronage Intentions. Dari penelitian ini dapat disimpulkan bahwa Desian Toko berpengaruh terhadap Shopping Experience Cost maupun terhadap Store Repatronage Intentions, akan tetapi Store Repatronage Intentions tidak dipengaruhi oleh Shopping Experience Cost.

Berdasarkan temuan tersebut maka Toko Elektronik " $\mathrm{X}$ " perlu untuk memperhatikan desain toko yang dapat menarik pengunjung sehingga dapat menciptakan pengalaman yang positif yang pada gilirannya akan menyebabkan mereka bersedia untuk melakukan pembelian ulang di toko tersebut..

Toko Elektronik " $\mathrm{X}$ " hendaknya menjaga penataan toko selalu menarik dengan penataan barang dagangannya yang kreatif dan memberikan kemudahan bagi pelanggan untuk mencari barang yang dibutuhkan, sehingga pelanggan tidak menjadi kebingungan mencari barang, bosan pada penataan dan terus tertarik pada barang-barang yang tersedia. 
Selain itu, Toko Elektronik "X" hendaknya memperhatikan kecenderungan waktu berkunjung pelanggan, sehingga para pelanggan tidak berkunjung secara bersamaan dan membuat pelanggan kurang menikmati pencarian kebutuhannya. Waktu kunjungan dan pencarian kebutuhan pelanggan dapat dialihkan dengan mengadakan program promosi diluar akhir minggu, seperti diskon khusus pada hari Senin-Jumat, acara nonton bersama diantara hari Senin-Jumat, dll.

Penelitian ini menggunakan setting toko yang menggunakan konsep hands-on display untuk menguji pengaruh Desain Toko terhadap Repatronage Intentions. Untuk menguji hubungan kausalitas antara variabel tersebut secara lebih umum, maka disarankan agar dalam penelitian berikutnya digunakan setting toko yang tidak menggunakan konsep hands-on display, sehingga dapat dilihat apakah perbedaan konsep desain toko dapat menimbulkan pengaruh yang berbeda terhadap Store patronage Intentions.

\section{DAFTAR KEPUSTAKAAN}

Andreu, L., E.Bigné, R. Chumpitaz and V. Swaen. 2006. How Does the Retail Environment Influence Shoppers' Emotional Experience? Evidence from Two Retail Settings, Working Paper. Louvain School of Management.

Arnould, E., G. Zinkhan, and L. Prince. 2002. Consumers. McGraw-Hill.

Baker,J. 1986. The Role of The Enviroment in Marketing Services, In : J.A. Czepeil, C.A. Congram e. J. Shanahan (eds), The Services Callenge: Inetegrating for Competiting Advantage, 79-84. Chicago: The American Marketing Assosiation.

. . . . . A. Parasuraman, D. Grewal, Glenn B. Voss. 2002. The Influence of Multiple Store Enviroment Cues on Perceived Merchadise Value and Patronage Intention. Journal of Marketing, Vol.66, 120-141.

... . and Michael Levy. 2002. Wait Expectations, Store Atmosphere and Gender Effects on Store Patronage Intentions. 5ème colloque Etienne THIL. 
Berman, Barry and Joel R. Evans. 2001. Retail Management: A Strategic Approach. Eight Editions. New Jersey: Prentice Hall.

Bitner, Mary J. 1990. Evaluating Service Encounters: The Effects of Physical Surroundings and Employee Responses. Dalam: Bitner, MJ. 1992. Servicescapes: The Impact of Physical Surroundings on Customer and Employees. Jurnal of Marketing 56, April, 57-71.

Bitner, MJ. 1992. Servicescapes: The Impact of Physical Surroundings on Customer and Employees. Jurnal of Marketing 56, April, 57-71.

Botschen,G and D. Crowther. 2001. The Semiology of Asetetic Atmospherics To Study Enviromental Design Effects in Retail Outlets. Studies in Social Marketing Working Paper Series No. 9. University of North London.

Balckwell. R.D., J. F. Engel, \& P. W.Miniard. 1995. Consumer behavior, 8th ed. Texas: The Dryden Press.

Donovan, Robert and Jonh Rossiter. 1982. Store Atmosphere: An Enviromental Psychology Approach. Journal of Retailing, Vol.58,34-57.

Engel, Blackwell and Miniard. 1995. Consumer Behavior, $8^{\text {th }}$ Editions. New York: The Dryden Press.

Frasquet, M., Vallet, T. and Gil, I. 2002. Key factors in shopping centre management: evidence from Spain. The International Review of Retail, Distribution and Consumer Research, 12(4), p. 337-54.

Fishbein, Martin and Icek Ajzen. 1975. Belief, Attitute, Intention, and Behavior: An Introduction to Theory and Research, dalam: Jones, M.A. and Reynolds, K.E. 2006. The Role of Retailer Interest On Shopping Behavior. Jounal of Retailing, Vol 82 (2), p. 115-126.

Greenland, Steve dan Peter J. McGoldrick. Measuring The Atmospheric Impact on Customer . Studies in Social Marketing Working Paper Series - ISSN 1472-9059. $\underline{\text { www.londonmet.ac.uk }}$

Hughes, Dr. 2005. Memory and Cognition: Museum of The Mind Project. Psychology 312-01.

Hui, M., L.Dubé, and J.Chebat. 1997. The Impact of Music on Consumer's Reactions to Waiting for Services", Journal of Retailing, 73(1). P. 87-104.

Jarnow, J., \& M.Guerreiro. 1991. Inside the fashion business. New York: Macmillan.

Jones, M.A. and Reynolds, K.E. 2006. The Role of Retailer Interest On Shopping Behavior. Jounal of Retailing, Vol 82 (2), p. 115-126. 
Kotler, Philip. 1973. Atmospherics as a Marketing Tool. Jounal of Retailing, Vol 49 (4), p.48-64.

. . 2003. Marketing Management $11^{\text {th }}$ Edition. New Jersey: Prentice Hall.

Lemmink, J. and Mattsson, J. 1998. Warmth during non-productive retail encounters: the hidden side of productivity, dalam: Jones, M.A. and Reynolds, K.E. 2006. The Role of Retailer Interest On Shopping Behavior. Jounal of Retailing, Vol 82 (2), p. 115-126.

Lewison, D. M. 1994. Retailing, $5^{\text {th }}$ Ed. New York: Macmillan College Publishing Company.

Lovelock, Christopher and Lauren K.Wright. 2005. Priciple of Service Marketing and Management. Terjemahan. Jakarta: PT Indeks .

Marketing. 2004. Konsepnya Hands-On Display. Edisi 3/IV.

Meyo, Letecia Nicole. 2000. Influence of Shopping Orientations, Selected Environmental Dimensions with Apparel Shopping Scenarios, and Attitude on Store Patronage for Female Consumers, Dissertation. Virginia: Faculty of the Virginia Polytechnic Institute and State University.

Ortony, Andrew and Terence J. Turner. 1990. What's Basic about Basic Emotions?, dalam: Jones, M.A. and Reynolds, K.E. 2006. The Role of Retailer Interest On Shopping Behavior. Jounal of Retailing, Vol 82 (2), p. 115-126.

Utami, Christina Whidya. 2006. Manajemen Ritel: Strategi dan Implementasi Ritel Modern. Jakarta: Penerbit Salemba Empat.

Wakerield, Kiric W, and Jeffrey G, Blodgett. 1999. Customer Response to Intangible and Tangible Service Factors. Psychology and Marketing, 16 Januari, 51-68.

Wikström, Solveig. 2005. The Role of Firms for Consumer Experience Creation. SE-106 91. Stockholm: Stockholm University School of Business.

Zeithaml, V.A., L.L.Berry, and A.Parasuraman. 1996. The behavioural consequences of service quality. Journal of Marketing. Vol 60, p. 31-46. 